\title{
HIV/AIDS Prevention in China: A Challenge for the New Millennium
}

\author{
Derek R. SMITH ${ }^{1,2}$, Ning $\mathrm{WEI}^{3,4}$, Peter A. LEGGAT ${ }^{2}$ and Rui-Sheng WANG ${ }^{1}$ \\ ${ }^{1}$ Department of Hazard Assessment, National Institute of Industrial Health, Kawasaki, Japan \\ ${ }^{2}$ School of Public Health and Tropical Medicine, James Cook University, Townsville, Australia \\ ${ }^{3}$ EU-China Volunteer Counselling and Testing (VCT) Project, Beijing, China \\ ${ }^{4}$ Third Teaching Hospital, Hebei Medical University, Shijiazhuang, China
}

\begin{abstract}
China's first HIV infection was officially reported in 1985 and by the end of 1996, there may have been up to 200,000 people affected nationwide. In 2001, this figure probably exceeded 600,000 . By 2003 , the predicted number of $\mathrm{HIV}$ cases had reached 1.5 million. At least 80,000 individuals now have fullblown AIDS. China may soon have the largest HIV-infected population in the world, possibly 6 million cases by 2005 . With infection rates rising at about $30 \%$ per year, it is feared this figure might exceed 10 million by 2010. Although the Chinese government was initially slow to accept the problem, in the late 1990s definite changes began occurring. In 2003 Premier Wen Jiabao publicly shook the hand of an AIDS patient and his government promised to introduce a range of free HIV-related services. Large preventive education campaigns are now underway. Unfortunately, there will still be many obstacles in controlling the epidemic and preventing further spread of this disease. Without doubt, China faces a serious predicament in the new millennium, and one which will pose numerous challenges for preventive medicine.
\end{abstract}

Key words: HIV, AIDS, China, prevention, public health

\section{Introduction}

China's first AIDS case was officially reported in 1985 in Yunnan Province, adjacent to the border with Burma (1). By the first half of 1995, a total of 1774 patients had been identified (2). In 1996 it was estimated that there were probably between 150,000 and 200,000 people affected nationwide (3). According to the Chinese Ministry of Health however, there were only 8303 cases officially recorded by October 1997 (3). By September 2001, this official number had risen to 28,133 , although estimates suggest that it most likely exceeded 600,000 (4). Until 2002 , the Chinese government maintained that there were only about 30,000 HIV cases nationwide, although their official count was later revised 25-fold upwards to 840,000. By 2003 the United Nations had estimated that the number of cases was closer to 1.5 million (5). In the first half of 2001 alone, China's HIV incidence rate increased by $67 \%(6)$, and at least 80,000 people now have full-blown AIDS (7). The Chinese Academy

Received Aug. 4, 2004/Accepted Dec. 13, 2004

Reprint requests to: Derek R. SMITH

Department of Hazard Assessment, National Institute of Industrial Health, Kawasaki 214-8585, Japan

TEL: +81(44)865-6111, FAX: +81(44)865-6124

E-mail: smith@niih.go.jp of Preventive Medicine finally acknowledged in 2001 that they may soon have the largest HIV infected population in the world, possibly 6 million cases by 2005 (8). With infection rates now rising at about $30 \%$ per year, the United Nations estimates that China may have more than 10 million HIV positive patients by 2010 (9). Given this alarming situation, we considered it necessary to conduct an in-depth literature review on the topic. We conducted a detailed literature search using standard internetbased medical search engines. We also retrieved some older documents from library archives and identified other material from the reference lists of published papers. An up-to-date reference list of HIV/AIDS in contemporary China appears at the end of our manuscript.

\section{The Epidemiology of HIV in China}

The three phases

Most epidemiologists agree that HIV spread through China in three distinct phases (10). The first phase (the entry phase) occurred between 1985 and 1988, involving a small number of imported cases, and was officially viewed as a 'foreign' problem (4). In 1987, China's Health Minister suggested the disease might be curtailed because sexual promiscuity and homosexuality were limited. HIV infected foreigners were subsequently banned from living in China, and it was also noted 
that it was illegal for Chinese citizens to have sex with foreigners (10). The second phase (the spreading phase) occurred between 1989 and 1993, with the detection of HIV cases among minority groups from Western province communities that bordered Myanmar, Laos and Vietnam (4). The third phase (the expansion phase) seems to have begun around 1994 (4), although several aspects of the 'expansion phase' and the 'spreading phase' were probably overlapping. In 1995, an article appeared in the scientific literature describing a mother and her two daughters who had become HIV infected after donating plasma (11). This was followed by a Chinese newspaper story in 2000 titled 'Strange disease in a Henan village shocks top officials,' and one which later appeared on the US Embassy web site (12).

\section{HIV transmission via blood donation}

Blood selling in Henan Province probably created China's first significant HIV reservoir. Traditional Chinese taboos against blood donation made blood-buying a profitable venture, with entrepreneurs visiting many rural areas and collecting blood from poor villagers and townsfolk (8). The first case of HIV acquired through plasma donation was reported in 1995 (11). In the 1990 s it was estimated that $70 \%$ to $90 \%$ of Chinese blood reserves were obtained from people who sold their blood commercially (2). Approximately 1 million poor farmers trying to supplement their incomes regularly donated blood in Henan province during this period (6). Unsanitary conditions and limited or non-existent infection control procedures contributed to the early spread of HIV. However, it was the practice of donating plasma only that enabled multiple donations from the same individual, who was presumably encouraged by the notion of multiple payments. In this manner, blood was centrifuged and the plasma removed, before pooling red blood cells from multiple donors and then reinjecting the mixture back into the original donor (10). Plasma selling not only disseminated HIV infection more widely, but it also ensured high viral titres in recipients of contaminated blood. It is estimated that up to 250,000 blood donors became HIV positive from blood donation during the 1990s (13). In Donghu village for example, over 600 villagers sold their plasma to blood companies, among whom 231 became HIV positive (13). In Wenlou village Henan, over $60 \%$ of the population are now HIV positive (6). The overall HIV prevalence among former blood donors now appears to range from $1 \%$ to $40 \%$, depending on the individual village (13).

\section{The government response}

Although the Chinese government initially responded to the Henan outbreak by banning journalists and international aid workers (13), it eventually addressed the issue of unsafe blood donation and officially banned the practice of pooled donations. Their countermeasures were reasonably successful, with few blood-donation-related HIV cases appearing after 1996 (8). Nonetheless, the spreading phase probably never ended as such; rather it was superseded by the expansion phase as HIV positive individuals began unknowingly infecting others. This situation was facilitated by a number of interrelated and complex social factors that China faced as it rapidly industrialised and social freedoms increased. HIV now has a firm foothold in Chinese society, with HIV-1 subtypes now including A, B, Thai B, C, D, $\mathrm{E}, \mathrm{F}$ and $\mathrm{G}$, as well as $\mathrm{BC}$ and $\mathrm{BB}$ recombinants (4).

\section{The Transmission of HIV}

\section{Intravenous drug users}

Intravenous drug users represent one of the most important social groups for HIV transmission in contemporary China, with approximately $60 \%$ to $70 \%$ of reported HIV infections occurring within this demographic (4). Most appear to be men aged between 20 and 29 years of age (8). Interestingly, some investigations have revealed that the HIV prevalence rate may be higher among female drug users than males (1). Either way, their overall number has certainly increased rapidly in recent years. For example, there were officially 170,000 drug users nationwide in 1993, a figure which increased to 400,000 in 1994 (2). By 2001, the official population of drug users was put at 900,000 (4). The prevalence of HIV among drug users, although variable from study to study, is known to be uniformly high. In Yunnan province, bordering Burma, almost half of all Heroin users are infected. In Xinjiang province, some studies have shown a HIV prevalence rate of $85 \%$ among drug users (8). It has been demonstrated that after 1 year of injecting drug use, the prevalence of HIV infection reaches $68 \%$ (1). HIV infection also occurs in conjunction with Hepatitis C Virus (HCV) and other blood-borne diseases. A recent study of drug users in Sichuan province showed the prevalence of HCV and HIV to be $71 \%$ and $11 \%$ respectively (14). HIV has now spread to all 30 provinces throughout China (6). At present, Yunnan has the highest number of HIV infected persons, representing approximately one-quarter of all reported cases. In Dehong for example, more than $1 \%$ of all pregnant women now suffer from HIV (15). Although Yunnan is one of China's poorest provinces, increased foreign trade in recent years has paradoxically improved the economy while simultaneously facilitating the spread of HIV (16).

\section{Heterosexual transmission}

HIV in China is also being spread via sexual contact and heterosexual transmission now accounts for about $7 \%$ of all cases (4). There are a few reasons for this trend. Firstly, an increasing proportion of the country's youth are no longer waiting until marriage before they have sex (6). This large demographic of 15 to 24 year old persons is estimated at approximately 210 million (6). A history of multiple sex partners is also increasing among young Chinese, especially in the more urban areas. Traditional Chinese conservatism has made it difficult to talk openly about sexual matters, particularly in the older generation. Lack of public health knowledge regarding HIV/AIDS also represents a problem, with many contemporary Chinese knowing very little about sexually transmitted diseases and their prevention (5). A recent survey showed that less than $3 \%$ of people were aware that condoms minimized the risk of HIV infection and only $21 \%$ knew they could be infected through sexual intercourse. Furthermore, almost $20 \%$ of the respondents had never even heard of HIV or AIDS (5). 


\section{Commercial sex workers}

Prostitutes represent another important social group for HIV transmission, and similar to injecting drug users, their numbers have been steadily increasing in recent years. According to the Ministry of Public Security, 137,000 prostitutes and their clients were arrested in 1990, 240,000 in 1992 and 400,000 in 1993 (2). This number had risen to 700,000 by the late 1990s (1). The overall number of prostitutes in modern China is now believed to exceed 3 million. Among them, high levels of HIV and other sexually transmitted disease have been revealed. Research in Yunnan and Guangxi demonstrated the HIV prevalence among sex workers to be about $5 \%$ and $11 \%$, respectively (6). Concurrent gynaecological infections may also facilitate sexual transmission of HIV, particularly in rural communities (6). In this regard, prostitute arrest records have revealed that the majority of commercial sex workers have at least one active, sexually-transmitted disease (17). Prophylactic usage is not widely practiced among Chinese sex workers. Estimates of condom usage among prostitutes ranges from $1 \%$ to $30 \%$ (1). Condom usage usually depends on the customer. Some studies have shown that most prostitutes have never had formal sex education (17). Many of them are also intravenous drug users, while sexually transmitted diseases are commonly treated with over-the-counter medicines. As prostitution is officially illegal in China, many infected sex workers are understandably reluctant to seek help or make themselves available for HIV testing and counselling.

Their customer demographic is also concerning. A recent study of prostitution users showed that their main clients were middle-class men under the age of 35. Men with the highest incomes were considerably more likely to have bought sex than those less well-off (6). In this manner, commercial sex workers may transmit HIV to their married clients, who will then transfer it to their families. Another factor compounding prostitution usage is the traditional social preference for male children, which became particularly acute following China's one-child policy (10). There is now an increasing demographic trend for males to outnumber females, with the rate currently believed to be about 120 males for every 100 females (18). This situation has resulted in less available women for sexually active males, which in turn, encourages or even necessitates prostitution usage. The problem may not be temporary either. From current figures it is anticipated that, over the next decade, around 10 to 15 million young Chinese men will have zero future prospects for marriage. This large demographic of unmarried men may be destined to find no sexual outlet during their lives other than commercial prostitution (10).

\section{Homosexual transmission}

Homosexual transmission is another probable HIV vector in China, with the number of gay men currently estimated at between $5 \%$ and $7 \%$ of the total male population (18). Men who have sex with men probably represent a group of between 2 and 8 million people (19). A survey of Chinese college students in the 1990s suggested that up to $8 \%$ may have homosexual tendencies (2). Interestingly, around $80 \%$ of gay Chinese men are currently married (6). Approximately $2 \%$ of married Chinese in rural areas engage in homosexual activities, a higher rate than for urban areas (4). Although homosexuality was removed from the official list of mental disorders in 2001, it remains illegal and highly stigmatized throughout Chinese society (1). The problem may worsen in future years if China's homosexual remains highly marginalised. In the year 2000 for example, gay men comprised one-third of all AIDS patients in two dedicated AIDS care hospitals in Beijing (6).

Furthermore, safer sex appears not to be widely practiced among China's homosexual community. For example, a recent study showed that condom usage, either with heterosexual or homosexual partners, occurred less than $10 \%$ of the time (6). Another investigation revealed that homosexual Chinese men may often engage in bisexual behaviour and/or paid sex with commercial sex workers, thereby expanding their range of potential contacts (20). This latter point is particularly important, as HIV prevalence is probably increasing among homosexual communities within China. A study of homosexuals recruited in Beijing for example, demonstrated that the HIV prevalence was about $3 \%$ and was independently associated with being older than 39 years and having more than 20 male sexual partners (19).

\section{Itinerant workers}

Another of China's major HIV carriers appears to be the increasing number of itinerant workers who are for the most part, young, poorly educated labourers, in a sexually active period of their life (10). During the Maoist era, a strict system of household registration kept most people confined to the immediate area in which they lived. With China's increasing economic prosperity and personal freedoms, such limitations were lifted and people were freely able to travel around. Rapid modernisation and industrial development also contributed to this demographic (4). The situation was compounded in poorer rural areas, where many young people left their hometown in search of a more prosperous life in urban centres (18). Additionally, there were around 40 million workers who became unemployed when previously state-owned enterprises failed due to free-market economic reform. Itinerant workers now number at least 120 million (6). Most of them are between 15 and 45 years of age, and by the nature of their demographic, represent a floating population that is difficult to educate, monitor and treat. They typically travel between their rural hometowns and cities seeking itinerant work, thereby providing an ideal vector for the extensive dissemination of HIV infection to remote areas (10).

Although prostitution is illegal in China as previously noted, commercial sex workers are readily available to itinerant workers and other travelling subpopulations such as longdistance truck drivers (21). Again as previously noted, condom usage is not widely practiced among prostitutes, HIV knowledge and preventive measures are not well known; and like their nomadic clients, commercial sex workers themselves are also a very mobile subgroup. China's itinerant workforce does not represent the only mobile vectors however. Newfound economic prosperity and individual freedoms have made international travel possible for many, with almost 100 million people visiting China in 2002 and around 17 million Chinese travelling abroad (21). These individuals may also provide 
additional vectors for HIV dissemination and importation.

\section{Government Interventions for HIV}

\section{Denial and inaction}

Although China's first HIV patient was reported almost 20 years ago, official government reaction was initially unrealistic and suboptimal. This situation was also compounded by a general community belief that HIV was simply a 'foreigners' disease that must be kept out (3). Most early programs targeting HIV seem to reflect such notions. Even early predictions of HIV prevalence were hopefully optimistic, suggesting that it might only affect between 50,000 and 250,000 by the year 2000 (2). As previously noted however, the real figure was probably double or triple these early government estimates. In many ways, Chinese officials were reluctant to acknowledge that their country was beginning to suffer from a disease, which was at the time, often associated with sexual promiscuity or moral degeneration (8). The HIV issue appears to have been essentially ignored until the summer of 2002 (7), by which time the national HIV reservoir had probably reached a critical figure of 1 million. The problem was not solely due to central government inaction however, with local government officials in Henan province (one of the worst hit areas) often detaining aid workers, journalists and other health workers in futile attempts to cover up their own regional epidemics (7).

\section{The gathering of momentum}

Although the gallant efforts of various individuals undoubtedly occurred behind closed doors for many years during China's growing HIV epidemic, official and visible government response was essentially delayed until the late 1990s. In January 1997, the Chinese government announced that it would take positive steps to keep HIV infections below 1.5 million by 2010 (3). In November 2001, an unprecedented international meeting on HIV/AIDS was held in Beijing, combining the talent of over 2700 health care experts (22). Two important AIDS symposiums were also held in Beijing in November 2003, where guest speaker Bill Clinton warned that HIV might hinder China's continued economic progress (9). However, it was the unprecedented and highly symbolic handshake between Premier Wen Jiabao and an AIDS patient in late 2003 that reverberated strongly across the country (10). On World AIDS Day, December 1 , virtually every major media outlet published the handshake photo acknowledging this formerly taboo subject. Premier Wen even told the AIDS patients: 'You must have confidence. All of society cares about you' (5). In a country steeped in tradition and heavily influenced by symbolism, the message was clear. It was also the first time a high ranking official from the ruling party finally confronted the type of discrimination that HIV positive Chinese are burdened with on a daily basis (10).

\section{Acknowledgement of the problem}

On World AIDS Day 2003, China's health minister finally acknowledged that their government was probably not doing enough to fight the emerging HIV epidemic. He offered to expand four important services: free HIV testing, free antiretro- viral drugs, free care for HIV-infected mothers and free education for AIDS orphans (5). Most importantly the testing and treatment would be free for those who could not afford to pay for it themselves (23). Aggressive public health education and prevention campaigns are now underway in China, although their effectiveness may be limited and are yet to be adequately demonstrated (24). Nevertheless, in Yunnan Province, the government recently issued Regulation 121 which focuses on aggressive HIV education. Hotels with prostitutes must now offer condoms (15). A new HIV vaccine is also being developed at the Chinese Academy of Medical Sciences, and one which uses distinctly Chinese primates as the research instrument (25).

\section{Barriers to Effective HIV Intervention}

\section{China's health care system}

Although positive steps have now been taken by the Chinese government in combating HIV/AIDS, numerous challenges remain. One issue is the structural inadequacy of China's current health care system that was graphically revealed during the SARS outbreak (26). Tuberculosis offers another pertinent example of how these shortcomings may compound the situation. China now has twice the level of multi-drug resistant tuberculosis of other countries (7). Providing affordable and accessible health care to the general public has also become increasingly difficult following the introduction of free-market reforms in 1978. In this manner, the rural health cooperatives that once provided health insurance and affordable health care have now been effectively abolished (7). Furthermore, the 'middle tier' community hospitals which formerly dispensed a great proportion of total health care have also disappeared (27). Such facilities will be essential to the success of any future HIV treatment and prevention programs. Social inequalities are also problematic, as increasing numbers of Chinese hospitals now charge fees for services, thereby excluding those who cannot afford to pay. Drug users, prostitutes and itinerant workers represent important HIV-affected sub-populations that have limited capacity to pay for medical care and drug treatments.

\section{Prohibitive treatment costs}

Although antiretroviral medications (such as indinavir, efavirenz and nevirapine) are now available from Chinese hospitals, most HIV positive individuals still rely on traditional Chinese medicine (1). Many patients also alternate between traditional Chinese medicine and standardised pharmaceutical regimes, which in turn, creates problems with drug compliance and resistance. In one Beijing study for example, $20 \%$ to $30 \%$ of the subjects had become resistant to nevirapine after 9 months (24). The costs of these drugs are also prohibitive for many Chinese HIV patients, although the price has fallen considerably in recent years. In 2001 for example, the average annual cost was US\$10,000 (22). By 2004, this had fallen to US\$200 or US\$300 (7). Unfortunately, the drop in price was not uniform among all drug types and from all drug companies. For example, the main drug of choice for treating HIV in Africa and Thailand still remains prohibitively expensive in China (24). Although China has recently offered to provide free HIV 
drug treatment for those who cannot afford it themselves, it remains to be seen whether the country can keep such a bold promise. Nevertheless, it is estimated that these costs may be minimised to about US\$30 million per year, a figure which is probably affordable in the current economic climate (7).

\section{Inadequate identification of cases}

The accurate identification of HIV positive individuals represents another barrier to effective public health interventions in China's HIV/AIDS epidemic. For example, although an estimated 80,000 Chinese HIV patients now have symptomatic AIDS, less than 5\% have been identified (24). General knowledge regarding the biological mechanisms and public health implications of HIV also remains problematic. There appears to be a false sense of security among ordinary Chinese that HIV is a foreigners' disease which only affects marginal communities (26). A previous community survey demonstrated that only $3 \%$ of Chinese people were aware that HIV was transmitted through an exchange of bodily fluids. However, in the same study, 54\% of participants thought that sharing chopsticks could spread the disease (8). Lack of preventive knowledge is another serious issue hampered by limited HIV-related knowledge. Aside for hampering the ultimate success of public health intervention programs, this type of biological ignorance also stigmatizes people already carrying the virus, forcing them even deeper underground and away from potential sources of help.

\section{References}

(1) Portsmouth S, Stebbing J, Xu K, et al. HIV and AIDS in the People's Republic of China: A collaborative review. Int $\mathbf{J}$ STD AIDS. 2003; 14: 757-761.

( 2 ) Zhang KL, Wei C. Health care systems in transition: People's Republic of China. Part II: The Chinese health care system's response to HIV-AIDS. J Pub Health Med. 1996; 18: 266268.

( 3 ) Tomlinson R. China recognises AIDS problem. Br Med J. 1998; 316: 493.

( 4 ) Zhang KL, Ma SJ. Epidemiology of HIV in China. Br Med J. 2002; 324: 803-804.

( 5 ) Watts J. China faces up to HIV/AIDS epidemic. Lancet. 2003; 362: 1983

( 6 ) Kaufman J, Jing J. China and AIDS-The time to act is now. Science. 2002; 296: 2339-2340.

( 7 ) Watts J. China's shift in HIV/AIDS policy marks turnaround on health. Lancet. 2004; 363: 1370-1371.

( 8 ) Beach MV. 'Blood heads' and AIDS haunt China's countryside. Lancet. 2001; 357: 49.

( 9 ) Watts J. HIV could blunt progress in China, Clinton warns. Lancet. 2003; 362: 1636.

(10) Cohen J. Poised for takeoff? Science. 2004; 304: 1430-1432.

(11) Wu Z, Liu Z, Detels R. HIV-1 infection in commercial plasma donors in China. Lancet. 1995; 346: 61-62.

(12) Cohen J. A scoop of international proportions. Science. 2004; 304: 1439.

(13) Cohen J. An unsafe practice turned blood donors into victims. Science. 2004; 304: 1438-1439.

(14) Ruan YH, Hong KX, Liu SZ, et al. Community-based survey of HCV and HIV coinfection in injection drug abusers in Sichuan Province of China. World J Gastroenterol. 2004; 10: 1589-1593.

\section{The Future}

HIV/AIDS clearly represents one of the greatest challenges for preventive medicine in modern China. There are at least 1 million HIV positive individuals at present, and this figure may reach 10 million by the year 2010 . However, the situation is not hopeless. In particular, the SARS epidemic provided an important learning experience and a key to the future battle against HIV/AIDS in China. Firstly, it revealed some important deficiencies in the medical and political infrastructure. Secondly, and perhaps crucially, it captured the attention of the international community and China's top leadership (28). This may indicate tentative acceptance of the comprehensive response needed to combat the nation's greatest public health challenge. In some ways, Thailand can be seen as a role-model for HIV prevention within developing countries. Thailand has been particularly successful in reducing new HIV infections among prostitutes and military recruits with their $100 \%$ condom program (6), and this approach may be appropriate for China. Either way, there will be many obstacles in controlling the epidemic, not the least of which will be to change public perceptions of HIV and raise awareness of preventive measures. Whether the Chinese government can muster the resources needed to keep its bold promises is also unknown. What is certain is that China now faces a serious epidemic in the new millennium, and one which will pose numerous challenges for public health and preventive medicine.

(15) Cohen J. Changing course to break the HIV-Heroin connection. Science. 2004; 304: 1434-1435.

(16) Tomlinson R. China steps up battle against AIDS. Br Med J. 1996; 312: 1056.

(17) Gil VE, Wang MS, Anderson AF, et al. Prostitutes, prostitution and STD/HIV transmission in Mainland China. Soc Sci Med. 1996; 42: 141-152.

(18) Gill B, Chang J, Palmer S. China's HIV crisis. Foreign Affairs. 2002; March/April.

(19) Choi KH, Liu H, Guo Y, et al. Emerging HIV-1 epidemic in China in men who have sex with men. Lancet. 2003; 361: 2125-2126.

(20) Zhang B, Liu D, Li X, et al. A survey of men who have sex with men: Mainland China. Am J Pub Health. 2000; 90: 1949-1950.

(21) Thompson D. Pre-empting an HIV/AIDS disaster in China. Seton Hall J Diplomacy Int Relations. 2003; 4: 29-44.

(22) Beach M. China responds to increasing HIV/AIDS burden and holds landmark meeting. Lancet. 2001; 358: 1792.

(23) Koralage N. China to offer free HIV testing and treatment. Br Med J. 2004; 328: 975.

(24) Cohen J. A new treatment campaign, but with limited weapons. Science. 2004; 304: 1433-1434.

(25) Cohen J. Vaccine development with a distinctly Chinese flavour. Science. 2004; 304: 1437.

(26) Gill B, Thompson A. The impact of HIV/AIDS on business in China. China Business Review. 2003; July/August: 6-11.

(27) Browne D. The long march to primary health care in China: From collectivism to market economics. Public Health. 2001; 115: 2-3.

(28) Gill B, Thompson A. Learning from SARS. China Business Review. 2003; July/August: 8. 